\title{
SyNoPsis: A Novel Perspective on Schizophrenia
}

Psychiatric diagnosis continues to be a difficult task. It suffers from relatively low validity and reliability. As in somatic medicine, diagnostic progress should move from purely descriptive to more pathophysiologically based and finally to aetiological diagnoses of therapeutic relevance. With the recurrent release of new diagnostic criteria, the psychiatric nomenclature did improve over time [1]. However, its diagnostic validity and utility are still perceived as unsatisfactory for both clinical care and research purposes. The problems are manifold: variable clinical presentations over time in an individual, overlapping boundaries between different entities, a lack of specific biomarkers, great cultural influences on clinical presentation, and shifting boundaries between normality and abnormality. To some degree, these problems are also found in somatic medicine.

However, there is an additional, specifically psychiatric and psychological difficulty fundamentally influencing concept formation in psychiatry: when dealing with mental disorders, it matters whether you do this by using the purely descriptive psychopathology of Karl Jaspers (following the phenomenology of Edmund Husserl), a dualistic (Cartesian) attitude, or a strictly naturalistic (neurobiological) approach, and I do not think that you should compromise in this respect.

All three ways of thinking had their merits and - depending on the situation - still have their justification.
However, they cannot be mixed when establishing a diagnostic framework in psychiatry. And I think that the nosological, ontological, and aetiological problems in psychiatry can only be overcome by following modern philosophical and neuroscientific views with a naturalistic approach based on the neurobiology of the brain which respects the subjective experience of patients. Today we must accept that introspective judgments are just as fault prone as objective observation of behaviour using neuroscientific tools. For example, human behaviour is controlled to a large extent by the unconscious, which is only partially accessible to introspection or to verbal exploration by an examiner. Thus, a subjective account on personal experience is important but not sufficient.

When critically appraising the countless functional imaging studies of the recent years, one comes to the conclusion that the classic, theoretically developed psychological constructs of behaviour, cognition, and emotion do not match the way the brain works. This is also the reason why functional brain imaging studies should be interpreted with great caution. Brain processing does not follow our abstract logic; it works in different categories than it was conceived. Just think of the completely different anatomical brain structures which were found to be critically involved in recognizing emotional facial expressions such as happiness (bilateral orbitofrontal cortex) or disgust (right striatum-insula, left amygdala) [2].

\section{KARGER}

(c) 2017 S. Karger AG, Basel

E-Mail karger@karger.com

www.karger.com/nps
Dr. Christian Walter Hess, Professor Emeritus of Neurology

University Department of Neurology, University of Bern

Alpenstrasse 28

CH-3084 Wabern (Switzerland)

E-Mail christian.w.hess@ neuro.unibe.ch 
It seems that nature did not develop these tasks as homologous, equivalent brain processes in a singular category of identifying emotional facial play. It is a bit the same as in genetics: who would have predicted that one gene defect, such as is found in the fragile X syndrome, can cause such a variety of seemingly unrelated clinical signs as nocturnal enuresis, learning problems with mathematics, speech problems with stutter (some patients stay non-verbal), flat feet, hyperflexible limb joints, a narrow and elongated face with protruding ears and chin, seizures, behaviour of avoiding eye contact, ataxia, and tremor in adult life? It is the logic of the genes. In psychiatry, we must perhaps also get used to the idea of novel, unexpected, and perhaps counterintuitive diagnostic categories. And the hope may remain unfulfilled to find the one "key" for the whole group of schizophrenias that one day will permit a cure for all.
Engaging in the thorny problem of schizophrenia, Strik, Stegmayer, Walther, and Dierks (in this issue [3]) here present an uncompromising diagnostic approach firmly based on today's neurobiological empirical knowledge. It is the fruit of two decades of determined work, which I had the chance to follow personally. During these years I had many inspiring and exciting discussions on the matter with Werner Strik. And now, I think the presented concept has the makings of the inception of a true paradigm shift in psychiatric nosology. The concept of Strik and co-workers has the distinct advantage of allowing novel and specific therapeutic interventions. With the demonstrated therapeutic applicability, the diagnostic system meets the most important requirement. This may indeed give us new hope for patient care in psychiatry.

Dr. Christian Walter Hess, Bern

\section{References}

SyNoPsis: A Novel Perspective on Schizophrenia
1 Stein DJ, Lund C, Nesse RM: Classification systems in psychiatry: diagnosis and global mental health in the era of DSM-5 and ICD11. Curr Opin Psychiatry 2013;26:493-497.

2 Gorno-Tempini ML, Pradelli S, Serafini M, Pagnoni G, Baraldi P, Porro C, Nicoletti R, Umità C, Nichelli P: Explicit and incidental facial expression processing: an fMRI study. Neuroimage 2001;14:465-473.
3 Strik W, Stegmayer K, Walther S, Dierks T: Systems Neuroscience of Psychosis: mapping schizophrenia symptoms to brain systems. Neuropsychobiology 2017;75:100-116 